\title{
Organizações, Inovação e Administração Estratégica
}

A questão da inovação no contexto das empresas e organizações, no âmbito da estratégia, possui um papel relevante na administração estratégica. Esta, por seu lado, confere maior dinamismo e flexibilidade ao processo estratégico, superando a relativa inércia de muitas operacionalizações do planejamento estratégico. Desse modo, a questão da inovação, quer ou não de índole tecnológica, no concerto das empresas, deve assumir notório papel estratégico. Perante os elevados graus de volatilidade no mundo empresarial e de negócios, que se acentuam pela presença obrigatória da inovação, faz-se necessário a presença da abordagem estratégica, de modo que as mesmas promovam os seus esforços inovativos e consigam obter vantagens competitivas.

Palavras-chave: Inovação; Organização; Estratégia.

\section{Organizations, Innovation and Strategic Administration}

This article aims to address the issue of innovation in the context of companies/ organizations, within the strategy, in which strategic management gains prominence. This, in turn, gives greater dynamism/flexibility to the strategic process, overcoming the relative inertia of many operations of strategic planning. Thus, the issue of innovation, whether technological or not, in the concert of companies/organizations, must take on a notorious strategic character. In view of the high degree of instability/volatility of the business/organization environment, which is accentuated by the obligatory presence of innovation, the strategic approach is required so that they promote their innovative efforts and gain competitive advantage.

Keywords: Innovation; Organization; Strategy.

Topic: Inovação Tecnológica

Reviewed anonymously in the process of blind peer.
Received: 15/10/2019

Approved: 21/12/2019
Manoel Gonçalves Rodrigues

Universidade Federal do Rio de Janeiro, Brasil

http://lattes.cnpq.br/5940113046592928

http://orcid.org/0000-0002-1014-5604

manoel.grodrigues@gmail.com

Fernando José Pereira da Costa

Universidade Federal do Rio de Janeiro, Brasil

http://lattes.cnpq.br/0908286687921354

fjpcosta@sapo.pt
Referencing this:

RODRIGUES, M. G.; COSTA, F. J. P.. Organizações, Inovação e Administração Estratégica. Revista Brasileira de Administração Científica, v.10, n.4, p.99-110, 2019. DOI:

http://doi.org/10.6008/CBPC2179-684X.2019.004.0007 


\section{INTRODUÇÃO}

A administração estratégica surge como elemento central no estabelecimento da relação interativo 'Estratégia/Resultado' no âmbito das empresas/organizações, notadamente para complementar as lacunas possivelmente deixadas pelo planejamento estratégico, que encontra dificuldades em acompanhar as rápidas mudanças ocorridas num meio envolvente cada vez mais acelerado e dotado de elevados graus de volatilidade.

Deste modo, a administração estratégica surge como forma de colmatar essas lacunas, de dar um direcionamento efetivamente estratégico/antecipatório às empresas/organizações e de fazer uma ponte com o planejamento estratégico, de modo a se constituir um efetivo sistema estratégico na empresa/organização, calcado no esquema 'Administração Estratégica $\leftrightarrow$ Estratégia $\leftrightarrow$ Planejamento Estratégico', de modo a apetrechá-la para lidar com os elevados graus de volatilidade do seu entorno empresarial/mercadológico, socioeconômico, sociopolítico, político-institucional e tecnológico. Na verdade, com a globalização, a desregulação das economias e dos mercados e os avanços tecnológicos das últimas décadas, ficou cada vez mais difícil acompanhar as variáveis afetas ao meio envolvente e geri-lo. Assim sendo, faz falta a administração estratégica, a inserir um certo quê de contingencial à administração das empresas/organizações, notadamente a nível do situá-las face às aceleradas mudanças do entorno.

Por outro lado, cabe considerar essa perspectiva a nível da inovação. De fato, a inovação passa a ter um papel cada vez mais importante para as empresas/organizações na busca pela vantagem competitiva geradora de resultados. Na verdade, a inovação (com destaque para a inovação tecnológica) introduz todo um conjunto de dinâmicas na vida da empresa/organização, nas suas estruturas internas, nos seus vínculos institucionais, no seu próprio funcionamento, no seu ambiente interno (processos de negócios, estrutura, objetivos, cultura, poder, tecnologia, finanças e preços), no seu ambiente imediato, competitivo ou setorial (fornecedores, consumidores, competidores, potenciais entrantes e substitutos) e no seu entorno mediato ou geral (econômico, político, sociocultural, ambiental, legal e tecnológico).

Num ambiente marcado pela elevada instabilidade no ambiente dos negócios, a inovação é variável sine qua non para a sobrevivência no mercado e a conquista de vantagens competitivas, sendo ela mesma, em si, geradora de elementos instáveis/voláteis para a empresa/organização que a promove, suas congêneres e o mercado no seu todo. Assim, para gerir todos esses impactos torna-se necessário dispor de um bem articulado sistema de administração estratégica.

\section{METODOLOGIA}

\section{Administração Estratégica}

No dizer de Camargos et al. (2003), se a estratégia corporativa, no conceito de Christensen (1999), Porter (1999) e Wright et al. (2000), deve ser vista como o grau mais abrangente dos demais níveis da estratégia organizacional, caso se venha a considerar a totalidade das condições da empresa/organização (dimensão, setor, estrutura, etc.), a administração estratégica deve ser considerada como a disciplina que 
caminha para uma constituição mais elaborada e até mesmo independente, da administração.

De fato, consoante é observado por Camargo et al. (2003), o nível de importância da administração estratégica para as empresas/organizações se deve tanto ao crescimento das suas dimensões, quanto ao aumento da sua própria complexidade estrutural. A isto se associando a aceleração do ritmo das mudanças a nível do entorno. Estas, por seu lado, exigem das empresas/organizações uma maior capacidade no que diz respeito à formulação/implementação de estratégias que permitam superar os cada vez maiores e mais complexos desafios do mercado e possibilitem o alcance dos objetivos de curto, médio e longo prazos. Para Camargos et al. (2003) e Meirelles (1995), a volatilidade do entorno pode estar ligada a fatores de ordem vária (desenvolvimento tecnológico, integração dos mercados, mundialização da concorrência, mudanças de carácter demográfico, câmbios nas preferências dos consumidores, redefinição do papel das organizações, etc.).

Como bem é assinalado por Camargos et al. (2003), a atual turbulência a caracterizar o entorno de negócios e que implica na consideração e ocorrência/interação de uma série de eventos (mudanças, competitividade, desempenho, posicionamento, missão, objetivos, resultados, integração, adequação organizacional, etc.) obriga a que a administração estratégica deva ser vista como um processo contínuo, no qual as estratégias devem ser constantemente revistas, uma vez que nem sempre se alcançam os objetivos pretendidos. Na verdade, uma estratégia pretendida pode ser realizada em sua forma original, modificada ou até mesmo de forma completamente diferente. Pode vir a ocorrer, em termos ocasionais, ainda que a estratégia pretendida pelo top management venha a ser implementada de fato. Contudo, na generalidade, há diferenças entre essa e a realizada, o que significa que a administração estratégica deve ser um processo contínuo e retroalimentável, com interações e retroalimentações constantes entre o previsto e o realizado, de modo a que a empresa/organização apresente sempre uma estratégia atempada e útil à consecução dos seus objetivos.

Para Fernandes et al. (2012), o processo no qual se insere a análise estratégica da empresa/organização implica na avaliação de uma série de itens afetos ao meio envolvente históricomercadológico (contexto de atuação, identificação dos riscos e descortinamento das oportunidades), quer em termos do meio envolvente imediato (mercado, negócios, concorrência, etc.), quer a nível do meio envolvente mediato (socioeconômico, político-institucional, jurídico-político e internacional). A considerar na análise meio ambiental deve estar também o avanço científico-tecnológico, a se traduzir pelo desenvolvimento de processos técnicos e produtos suscetíveis de afetar a atividade, produtividade e rentabilidade das empresas/organizações. No contexto da análise do meio envolvente das empresas/organizações ganha realce a análise/avaliação do entorno operacional (estrutura da indústria, ciclo de vida do setor, dimensão/crescimento do mercado, grau de atratividade do setor e estratégia da concorrência), que se consubstancia no modelo dos cinco forças de Porter (1986, 1989 e 1999) e que considera o impacto da entrada de novos competidores a nível da participação do mercado e da rentabilidade do negócio, com inferências em termos das necessidades de capital, diferenciação dos produtos, custos das mudanças, intensidade da concorrência, definição da estratégia competitiva, etc. 
Neste contexto, no dizer de Hitt et al. (2011), a inovação constitui-se no fator mais importante na determinação do êxito de uma empresa/organização deste século. Na verdade, apesar de muitas empresas/organizações terem se tornado altamente eficientes no último $1 / 4$ de século, elas precisarão ser extremamente inovadoras no $1 / 4$ de século vindouro e nos anos que a este se seguirão, de modo a que sejam capazes de criar vantagens competitivas sustentáveis. O grau de importância assumido pelas inovações cresceu enormemente nos últimos anos, em razão do vertiginoso aumento da concorrência. Na verdade, o que ocorre em vários setores é que as melhorias incrementais, seja a nível dos produtos, quer em termos dos processos, já não se mostram suficientes para dar sustentação às vantagens competitivas obtidas.

Logo, para assegurar a manutenção dos níveis de competitividade das empresas/organizações, há que apostar na inovação contínua, uma vez que as vantagens competitivas têm um prazo limitado de vida (os benefícios da estratégia de criação de valor de uma empresa/organização podem ser apropriados pela concorrência a partir da imitação). Efetivamente, a sustentabilidade de uma vantagem competitiva irá depender de três fatores: o índice de obsolescência das competências essenciais em razão de mudanças ambientais, a disponibilidade de substitutos da competência essencial e a imitabilidade da competência essencial. Logo, só com um fluxo constante de inovações (a inovação como variável básica da administração estratégica) é possível romper com essas restrições.

Para Hitt et al. (2011), tão ou mais importante do que o contexto concorrencial são as capacitações que as empresas/organizações consigam criar, no sentido de gerar vantagens competitivas, conduzindo-as à obtenção de vantagens competitivas, de modo a obter competitividade estratégica e retornos acima da média e alcançar a dianteira face à concorrência. A empresa deve analisar o seu ambiente interno (recursos, capacitações e competências) e de buscar a criação de valor. O processo de administração estratégica ultrapassa assim o simples entendimento do setor, passando a ter nas competências as componentes mais importantes da vantagem competitiva.

Por outro lado, a análise da cadeia de valor é um importante instrumento para que a empresa/organização perceba onde cria ou não valor, uma vez que a cadeia de valor mostra como um produto vai da matéria-prima até o cliente final. Para as empresas, a ideia básica da cadeia de valor é criar valor adicional sem incorrer em custos significativos e captar o valor criado. Na realidade, a empresa/organização só obtém retornos acima da média se o valor que ela cria for maior do que os custos incorridos para criá-lo. Entretanto, a análise da cadeia de valor é utilizada para identificar/avaliar o potencial competitivo dos recursos/capacitações da empresa/organização, buscando a compreensão da sua estrutura de custos e a identificação das atividades passíveis de geração de valor.

Por outro lado, em razão do que é assinalado por Alday (2000), com a rápida mudança das ambiências (social, política, econômica, tecnológica, etc.) das empresas/organizações, o planejamento estratégico surge como técnica adequada ao tratamento desses ajustes, constituindo-se num elemento de extrema relevância de reflexão/ação e com um estreito vínculo com a administração estratégica. Assim, o plano estratégico permite definir a direção a ser seguida pela empresa/organização de modo a buscar uma maior interação da mesma com o entorno. 0 planejamento estratégico e a projeção futura acabam por divisar a estratégia, mas 
o norte para a premissa criativa dessa relação é a administração estratégica, que fornece uma clara compreensão sobre a organização no âmbito do seu setor de atividade e dimensão. Define-se a administração estratégica como um processo contínuo/interativo que objetiva a manutenção de uma empresa/organização como um conjunto integrado ao meio envolvente. De fato, ao assim ser e ao esmiuçar a caracterização da empresa/organização, a administração estratégica potencializa o planejamento estratégico como instrumento norteador dos rumos a serem seguidos pela empresa.

Portanto, consoante registra Novais (2017) e Evans (1991), é neste contexto que se avança com o conceito de flexibilidade estratégica, relacionado à capacidade de adaptação e à modificação de cursos de ação face ao que fora anteriormente planejado relativamente às modificações ocorridas no meio envolvente externo. Assim, a flexibilidade estratégica associa-se à ideia de mudança e refere-se à questão da incerteza. O conceito de flexibilidade estratégica consiste numa abordagem alternativa de administração, envolvendo a possibilidade de explorar novos produtos/negócios e segmentos de mercado de forma mais célere/eficiente e se mostrando relevante em contextos de elevada intensidade tecnológica. Por outro lado, o conceito de flexibilidade estratégica relaciona-se à capacidade de induzir/responder mudanças inesperadas a nível da ambiência, de modo a se relacionar com os conceitos de versatilidade/agilidade, numa forte/intensa interação entre a empresa/organização e o meio envolvente. A flexibilidade estratégica impõe que empresa/organização seja capaz de identificar mudanças significativas a nível da sua envolvente externa, de modo a se Ihe antecipar de forma estratégica e assim criar uma vantagem competitiva, para tal direcionando os seus recursos.

\section{DISCUSSÃO TEÓRICA}

\section{Inovação}

Conforme relata Silva et al. (2013), no período que vai de 1938 a 1983 a Coréia do Sul, no contexto da economia-mundo, migrou da Periferia para a Semiperiferia, o que configurou a face mais visível do denominado milagre econômico do Leste asiático, no qual desempenharam um papel fundamental as inovações. A verdade é que segundo Silva et al. (2013), Laplane (1997) e Schumpeter (1993), a introdução das inovações no mercado conduz a rupturas de rotinas estabelecidas e a transformação de estruturas existentes em um processo de mudança que seja deflagrado através das inovações. De fato, toda e qualquer inovação desencadeia um processo de destruição das estruturas. Introduzindo-se inovações no mercado, ocorrem rupturas que geram instabilidades de uma forma cíclica. Estas instabilidades dizem respeito especificamente às condições mercadológicas.

Efetivamente, podemos afirmar que as inovações se constituem na utilização de recursos produtivos/comerciais que colocam em cheque a estabilidade da ordem e as condições sociais nas quais se baseia. As inovações podem se resumir à utilização de recursos produtivos de uma forma até então inexistente, conduzindo a uma descontinuidade do sistema. Na verdade, ao se abordar o caso das inovações tecnológicas, estas implicam em diferentes graus de conhecimento e em certas condições de uniformidade 
tecnológica e (re) definindo-se trajetórias de avanços tecnológicos. Na verdade, a inovação emerge do campo do conhecimento, o qual se encontra envolto no projeto inovativo.

De acordo com o que é apontado por Sanches et al. (2013), Freeman et al. (2008), Schumpeter (1997), Piscopo (2010) e Lavarda (2009), a necessidade de sobrevivência/crescimento faz com que as empresas/organizações desenvolvam capacidades com o intuito de se adaptarem constantemente às mudanças advindas do entorno (mercadológico, econômico, social, institucional, tecnológico, etc.). $\mathrm{Na}$ verdade, a inovação é vista como um processo que transforma novidades (ideias, produtos, serviços, formas de trabalho, etc.) em oportunidades, uma vez que sejam aceitas/aproveitadas, de forma a tornarem-se formas comumente adotadas/utilizadas, impactando a estrutura dos mercados e afetando o desempenho das empresas e organizações. É neste ponto que se insere o conceito de inovação tecnológica, relevante para qualquer ramo/setor de atividade, sendo necessário ressaltar a sua relevância/pertinência no caso das empresas de base tecnológica, ou seja, os que possuem a inovação tecnológica como fundamento da sua estratégia competitiva. De fato, a partir de um diferencial competitivo, as empresas desenvolvem suas estratégias de inovação. Estas, por seu lado, podem ser tidas como orientações direcionadas ao comportamento inovador. Assim, o processo de inovação surge de novas práticas em diversas rubricas (produtos, processos ou serviços), pois toda a inovação é parte de uma estratégia que tem por propósito a própria inovação.

Consoante é destacado por Machado (2013), Van Der Ven (1986), Ahmed (1998) e Knox (2002), as novas condições que vêm caracterizando a dinâmica dos mercados desde finais do século transato (a concorrência acirrada, a abertura comercial das fronteiras e a massificação da própria internet) conduziram as empresas e organizações a buscar novas formas de manutenção/permanência no mercado. Para tanto, vêm colaborando as inovações técnicas (as novas tecnologias e serviços) e as inovações administrativas (novos procedimentos, políticas e formas empresariais/organizacionais). No entanto, um dos fatores mais importantes a estimular a inovação é a cultura organizacional, que pode tomá-la como valor ou ativo fundamental da empresa.

Nesse sentido, a inovação deve ser incentivada no contexto de um ambiente empresarial adequado. Como a capacidade de inovar situa-se nas habilidades/atitudes dos elementos atuantes na empresa/organização, o seu posicionamento enquanto entidade inovadora só se sustenta a partir da cultura empresarial/organizacional, conferindo-Ihe um diferencial competitivo. Por outro lado, cabe assinalar que as inovações de cunho empresarial/organizacional podem alterar processos/estruturas a envolver tomadas de decisão, com implicações a nível do relacionamento entre indivíduos, equipes e outros aspectos da vida da empresa/organização.

Na realidade, conforme atestam Machado (2013), Schumpeter (1985), Hayes et al. (1984), Jacobson (1992) e Rogers et al. (1971) o comportamento das empresas/organizações irá variar de acordo com as alterações que se vierem a verificar em seu ambiente interno (sejam elas de caráter administrativo, de processo, nas formas de poder, na tecnologia, na implantação de uma nova linha de produtos, na introdução de um novo conjunto de serviços, etc.). No entanto o fato é que o desempenho empresarial/organizacional 
é função da opção estratégica do top management das empresas/organizações e que uma opção estratégica é aquela que conduz a maiores lucros com maior produção e menores esforços (a inovação de mercado), a envolver a conquista de clientes através da oferta de produtos a menores preços. Efetivamente, formas alternativas de inovação podem ser implantadas no sentido de alcançar a melhoria em vários aspectos da vida de uma empresa/organização (processos internos, capacitação pessoal, capacitação profissional, posicionamento no mercado, resultados financeiros, dentre outros), cabendo observar ser o incentivo à produção contínua de inovações uma forma comprovada de obtenção de vantagens competitivas.

Neste campo, conforme atestam Machado (2013), Jacobson (1992) e Rogers et al. (1971), várias são as modalidades de inovação a concorrer para a maior competitividade empresarial e organizacional, desde processos e tecnologia, passando por métodos de organização/gestão da produção/trabalho ou a utilização de novos materiais e chegando mesmo a uma ideia (ou a um manancial de ideias). Em tempo, a inovação, quando se refere a um novo produto, pode implicar em menor custo de produção e comercialização, em novos conhecimentos, procedimentos ou num diferencial ao consumidor. De fato, as empresas irão requerer uma cultura organizacional voltada à criatividade (a capacidade de criar/inovar), possibilitando a geração de valor e a criação da vantagem competitiva à empresa criativa e inovadora.

\section{Inovação e Organização}

A inovação liga-se ao desenvolvimento das empresas/organizações, notadamente a partir do advento do capitalismo industrial. Com a Primeira Revolução Industrial inglesa dos séculos XVIII e XIX, a inovação fazia-se presente nas invenções dos empreendedores. Com a Segunda Revolução Industrial, de finais do século XIX aos anos 70 e 80 do século XX, institui-se a interação 'Laboratório/Fábrica', dando-se conteúdo claramente científico à produção industrial e à sua gestão (a administração científica de raiz taylorista), com a inovação assumindo papel cada vez mais relevante a nível do processo de produção e na conquista e consolidação de posições de mercado. Na Terceira Revolução Industrial (também dita Terceira Revolução Industrial e Tecnológica), as inovações de cunho tecnológico (robótica, informática, telemática, dentre outras) sedimentam um novo paradigma produtivo (e de gestão), consolidam a interação 'Indústria/Tecnologia' e preparam o cenário para o advir da Quarta Revolução Industrial (a Indústria 4.0), cada vez mais próxima e já sendo praticamente uma realidade em diversas áreas (manufatura aditiva, inteligência artificial, internet das coisas, biologia sintética, sistemas ciberfísicos, dentre outras), com elevadas perspectivas quanto aos possíveis níveis de produtividade. Desse modo, a inovação, em especial a de carácter tecnológico, assume a posição de variável estratégica básica da empresa.

Por outro lado, de acordo com Guerrero et al. (2007), a introdução das TIC (Tecnologia da Informação e Comunicação) no âmbito da esfera produtivo-industrial configura um conceito contemporâneo de produtividade. Este, por sua vez, constrói-se através da expansão dos investimentos em conhecimento científico e tecnológico, Pesquisa e Desenvolvimento (P\&D) e capital humano, promovendo a expansão dos investimentos em conhecimento/informação, que passam a se constituir em vetores de geração de riqueza (empresas, regiões e países), em elementos nucleares da mudança social, do progresso tecnológico e do 
desenvolvimento das economias avançadas e em fatores de alavancagem/sustentabilidade do ciclo de desenvolvimento econômico. A inovação/difusão, no que se refere aos conhecimentos científicos, tecnológicos e produtivos (mormente a nível da esfera produtivo-industrial), atuam como suporte à capacitação/aprendizado, notadamente em termos de produtos e processos (tecnológico-produtivos e inovativo-tecnológicos).

De fato, a nível do processo produtivo-industrial, enquanto fator de criação, viabilização e dinamização da competitividade, a inovação, em termos de produtos, tecnologias e processos, surge como elemento dinâmico, basilar e fulcral (portanto estratégico) no que se refere à construção de vantagens comparativas. Assim sendo, a capacidade em desenvolver/absorver novas tecnologias irá depender ou da articulação/interação das empresas/organizações produtivo-industriais com centros geradores/produtores de tecnologia (instituições de pesquisa, centros tecnológicos e universidades) ou da capacitação das mesmas, em razão da promoção de esforços próprios de $P \& D$, no que diz espeito à criação, aplicação e difusão de novos conhecimentos. De qualquer modo, se a criação endógena de tecnologia/inovação relaciona-se a esforços de P\&D (learning by searching), a empresa/organização industrial pode também ter acesso às inovações a partir de supridores externos.

De acordo com Zancul et al. (2006), as empresas com destaque para as organizações de cunho industrial, em razão da intensa dinâmica produtivo-concorrencial, calcada no processo de desenvolvimento tecnológico, mostram-se cada vez mais confrontadas com a necessidade de promover uma rápida intervenção a nível do lançamento de novos produtos no mercado, implicando em ritmo/tempo, áreas funcionais e pessoas e indo do início ao fim dos respetivos projetos (da concepção ao lançamento, passando pela elaboração). Toda esta dinâmica implica em novas formas de organização do trabalho, que ultrapassem, de forma significativa, o approach taylorista-fordista. A envolvente competitivo-mercadológica exige a concepção de novas formas de trabalho, que se mostrem cada vez mais flexíveis e capazes de atender as demandas do mercado de forma rápida e a baixo custo. Mesmo o modelo Toyotista, tido como mais de acordo com a configuração delineada pela Terceira Revolução Industrial e Tecnológica, pela sua comprovada flexibilidade, pode apresentar limitações com o advir da Quarta Revolução Industrial.

De acordo com Tidd et al. (2003), a introdução de inovações encontra-se relacionada à obtenção de vantagens comparativas, desempenhando o processo de inovação um papel efetivamente estratégico no que diz respeito à capacidade para desenvolver novos produtos, no contexto de um entorno extremamente cambiante, uma vez que possibilita às empresas/organizações a possibilidade de promover a atempada inovação do produto ou do respectivo processo de elaboração do mesmo, de modo a alcançar níveis superiores em termos de produtividade e competitividade, patamares mais elevados quanto à capacidade de produção, nítidas vantagens a nível do desempenho, indiscutíveis benefícios relativamente a métodos de produção e distribuição, óbvia preeminência com relação a novos conceitos que condenem os demais à obsolescência, etc. Neste contexto, um dos principais critérios de triagem quanto à introdução de uma inovação, principalmente tratando-se de uma inovação de cunho tecnológico (tecnologia de processo, por exemplo) tem a ver com o impacto sobre a redução dos custos de produção, o que deverá conferir maior 
competitividade às empresas/organizações.

Por sua vez, Gavira et al. (2007) reconhecem a importância da inovação para o crescimento/desenvolvimento das empresas/organizações, o que explicaria o porquê se busca promover/desenvolver novas formas/ferramentas no sentido de se otimizar a sua gestão. De fato, a seguir a abordagem schumpeteriana, a inovação se constitui numa fonte essencial a nível da competição efetiva, do desenvolvimento econômico e da transformação da sociedade. Na realidade, ainda de acordo com o approach schumpeteriano, a competição originada de um produto, processo ou organização (novos ou melhorados/aperfeiçoados) mostra-se como muito mais devastadora do que a competição não inovativa. Logo, a quantidade/complexidade das inovações têm aumentado rapidamente, sobretudo nos últimos anos. A acirrada competição surge como um dos principais elementos na procura pela busca competitiva por velocidade, eficiência e qualidade.

De entre esses aspectos são de destacar a crescente internacionalização dos mercados, o aumento da diversidade e variedade de produtos, a redução do ciclo de vida dos produtos no mercado, a mudança nos padrões de concorrência entre as organizações e as expectativas dos consumidores com relação à qualidade e à tecnologia. Em um ambiente extremamente competitivo/concorrencial, as empresas/organizações querem conquistar cada vez mais mercados, a partir da diferenciação dos produtos e alcançando vantagens competitivas sustentáveis. Assim sendo, a inovação passa a ser vista como uma espécie de necessidade premente. Em outras palavras, passam-se a ter novas oportunidades com relação a produtos/mercados. Logo, o desenvolvimento de processos mais eficientes para produzi-los passa a ser visto como crucial pela própria empresa.

\section{Inovação e Externalidades}

Observam Albagli et al. (2004) que nas transformações a ocorrer desde as últimas décadas do século XX, é nítido o papel estratégico assumido pelo binômio 'Informação/Conhecimento' em várias dimensões da vida em sociedade, tornando indissociável a interação entre várias dinâmicas cognitiva, informacional, inovativa e socioespacial. Assim, o conhecimento tácito assume-se como fonte de inovação/competitividade, com as interações locais assumindo um importante papel na produção/difusão desse mesmo conhecimento. Daí a conexão entre estes aspectos e toda uma gama de conceitos de capital social, territorialidade, redes, bem como das chamadas aglomerações produtivas - distritos industriais, clusters, milieux innovateurs, arranjos e sistemas produtivos e inovativos locais, que de um modo ou de outro acabam por remeter à questão da inovação. De fato, uma inovação ou um conjunto de inovações pode vir a fornecer a base técnica para novos modos de produção, valorização e reprodução ampliada de capital, seja a nível da sua componente financeira, quer em termos da sua variante produtiva, de modo a possibilitar a flexibilização do aparato técnico e do trabalho, viabilizando a produção, comercialização e circulação de um conjunto de bens (tal como ocorreu com as TIC). Contudo, isto não implica numa maior socialização dos conhecimentos estratégicos nem evita o agravamento das desigualdades a todos os níveis.

Para Albagli et al. (2004) e Cassiolato et al. (1999), há concepções que criam o ambiente propício a 
interações, aprendizado, trocas de conhecimento e interações, favorecendo/estimulando a inovação. As denominadas aglomerações produtivas, científicas, tecnológicas e/ou inovativas nos distritos industriais, clusters, milieux inovadores, arranjos produtivos locais, entre outros, criam um ambiente claramente favorável a esforços direcionados à inovação. Contudo, o que costuma predominar é a cooperação intencional, principalmente no caso de empresas (ou entre empresas e instituições de pesquisa), muito embora se deva considerar o envolvimento de outros atores de relevância para o sistema produtivo e tecnológico, a saber: clientes, parceiros, competidores, fornecedores de bens, equipamentos e serviços, universidades, institutos/centros de pesquisa, entidades reguladoras, associações empresariais, sindicatos, demais atores sociais, etc..

\section{Inovação e Estratégia}

A inovação, no contexto das empresas, desempenha um papel eminentemente estratégico, fulcral para thes conferir níveis mais elevados de competitividade e de avanço tecnológico e gerencial. A incorporação de inovações permite às empresas a modernização de seus processos e técnicas de produção e gestão, possibilitando assim o alcance de melhores resultados operacionais e de configurações tecnológicas altaneiras. A incorporação de inovações, por parte das empresas/organizações, seja a nível de processos, produtos, métodos ou técnicas, promove a sofisticação das organizações a vários níveis, destacando-se o avanço tecnológico. Os esforços de P\&D devem-se recrudescer em setores tecnologicamente mais intensivos/sensíveis, convertendo-se as empresas em centros criadores de inovação tecnológica. Contudo, cabe o registro que de acordo com a abordagem schumpeteriana, o conceito de empresário inovador não se aplica somente ao gerador/criador da inovação, mas àquele que a introduz no seio da empresa/organização.

De qualquer modo, a questão da inovação no contexto das empresas, assume um carácter nitidamente estratégico e como tal deverá ser contemplado pelo processo de planejamento estratégico, por sua vez guiado pelo processo de administração estratégica. Com isto, fornece-se flexibilidade à introdução/incorporação de inovações, mormente as de cunho tecnológico, incorporando-as a uma lógica de mercado dinâmica e não engessada por uma sequência de cronogramas irrealisticamente definidos e burocraticamente fixados, de modo a ceifar a criatividade/potencialidade da estratégia. Assim sendo, o planejamento estratégico pode ser visto como a sistematização a ser guiada/monitorizada pela essência estratégica (a administração estratégica), sendo nesse contexto que deve ocorrer o desenvolvimento e/ou a introdução da inovação. O escopo estratégico (planejamento estratégico + administração estratégica) ganha força/relevância principalmente quando se trata de inovações de carácter tecnológico e principalmente quando se referem a desenvolvimento próprio e capacitação a envolver intensos esforços em termos de P\&D.

\section{CONCLUSÕES}

A questão da inovação foi aqui abordada no contexto das organizações. Considerou-se ser a inovação em especial a tecnológica uma variável de forte pendor estratégico no contexto das empresas. Em muitos 
casos, a mais estratégica das variáveis a compor o contexto organizativo-empresarial. Para tanto, será fundamental considerá-la no âmbito do escopo estratégico da organização, tendo-a em conta a nível do plano estratégico e, num sentido mais amplo, dinâmico e flexível, em termos da administração estratégica.

A inovação como variável estratégica implica que a empresa passe a ser guiada pela componente schumpeteriana da análise econômica (o empresário inovador), com a inovação sendo criada e desenvolvida pelo próprio empresário ou gestor, e ao mesmo tempo introduzida pelo mesmo a partir de aquisição no mercado. Em ambas as situações se tem a inovação e em ambos os casos se depara com o inovador empresário/gestor. Ter a empresa na senda da inovação, a seguir a trajetória do empresário e gestor inovador, implica em defini-la, necessariamente, como variável estratégica, objetivo maior da empresa e recurso superior na conquista de maior competitividade.

A turbulência do entorno exige o recurso à 'âncora' estratégica, vale dizer a estratégia = análise estratégica mais planejamento estratégico mais administração estratégica, e é como variável estratégica que deverá ser tratada a inovação, mormente a de base tecnológica. A necessidade da abordagem estratégica ganha relevo quando existem externalidades de foro econômico, administrativo ou institucional a envolver a questão da inovação. Na verdade, só a postura estratégica poderá permitir o aproveitamento efetivo das sinergias possibilitadas por sistemas interagentes com a organização.

Neste contexto, somente num contexto efetivamente estratégico é que as organizações poderão desenvolver com sucesso os seus esforços no sentido de desenvolverem e/ou incorporarem inovações e conseguirem ganhar posições de destaque através da obtenção de vantagens competitivas a nível da criação de valor e da obtenção de resultados. A administração estratégica, ao suprir as lacunas do planejamento estratégico, permite um aggiornamento do referencial estratégico, reposicionando a organização perante a elevada instabilidade do seu entorno e criando o ambiente propício à ocorrência da inovação, em si mesmo fator interno e externo de volatilidade na vida da empresa e aqui a abordagem estratégica serve como âncora e direcionamento para a mesma. Logo, a administração estratégica se torna em elemento fundamental para posicionar a empresa diante da extrema turbulência que caracteriza hoje o seu meio envolvente de negócios e o geral, criando as condições propícias para o desenvolvimento e a incorporação de inovações, base para a criação de vantagens competitivas.

\section{REFERÊNCIAS}

AHMED, K. P.. Culture and climate for innovation. European Journal of Innovation Management, v.1, n.1, p.30-43, 1998.

ALBAGLI, S. E MACIEL, M. L.. Informação e conhecimento na inovação e no desenvolvimento local. Ciência da Informação, v.33, n.3, p.9-16, 2004.

ALDAY, H. E. C.. O planejamento estratégico dentro do conceito de administração estratégica. Revista FAE, v.3, n.2, p.9-16, 2000.

CAMARGOS, M. A.; DIAS, A. T.. Estratégia, administração estratégica e estratégia corporativa: Uma síntese teórica. São Paulo. Caderno de Pesquisas em Administração, v.10, n.1, p.27-39, 2003.

CASSIOLATO, J. E.; LASTRES, H. M. M.. Globalização e inovação localizada: experiências de sistemas locais no Mercosul. Brasília: IBICT, 1999.

CHRISTENSEN, H. K.. Estratégia Corporativa: Gerenciando um Conjunto de Negócios. In: FAHEY, L.; RANDALL, R. M.. MBA Curso Prático: Estratégia. Rio de Janeiro. Campus, 1999. p.67-99.

EVANS, J.. Strategic flexibility for high technology manoeuvres: A conceptual framework. Journal of Management Studies, v.28, n.1, p.69-91, 1991. 
FERNANDES, B. H. R.; BERTON, L. H.. Administração Estratégica: da Competência Empreendedora à Avaliação de Desempenho. São Paulo: Saraiva, 2012.

FREEMAN, C.; SOETE, L.. A Economia da Inovação Industrial. Campinas: UNICAMP, 2008.

GAVIRA, M. O.; FERRO, A. F. P.; ROHRICH, S. S.; QUADROS, R.. Gestão da inovação tecnológica: Uma análise da aplicação do funil de inovação em uma organização de bens de consumo. Revista de Administração Mackenzie, v.8, n.1, p.77-107, 2007.

GUERRERO, G. A. et al. Dinâmica inovativa e possibilidades de upgrade tecnológico em arranjo produtivo de calçados: um estudo de caso. In: ENCONTRO DE ECONOMIA DA REGIÃO SUL DA ASSOCIAÇÃO NACIONAL DE CENTROS DE PÓS-GRADUAÇÃO EM ECONOMIA, 10. Anais. Porto Alegre: ANPEC, 2007. p.1-20.

HAYES, R. H.; WHEELWRIGHT, S. C.. The Concept of Manufacturing Strategy: Restoring Our Competitive Edge: Competing Through Manufacturing. New York: John Wiley \& Sons, 1984.

HITT, M. A.; IRELAND, R. D.; HOSKISSON, R. E..

Administração Estratégica: Competitividade e Globalização. São Paulo: Cengage Learning, 2011.

JACOBSON, R.. The 'Austrian' school strategy. The Academy of Management Review, v.17, n.4, p.782-807, 1992.

KNOX, S.. The boardroom agenda: developing the innovative organization. Corporate Governance, v.2, n.1, p.27-36, 2002

LAPLANE, M.. Inovações e Dinâmica Capitalista. In: CARNEIRO, R.. Os Clássicos da Economia. São Paulo: Ática, 1997. p.59-67.

LAVARDA, R. A. B.. ¿Qué comportamientos estratégicos favorecen la innovación en la organización?. Revista de Administração e Inovação, v.6, n.3, p.145-162, 2009.

MACHADO, D. D. P. N.. Cultura de inovação: elementos da cultura que facilitam a criação de um ambiente inovador. Revista de Administração e Inovação, v.10, n.4, p.164-182, 2013.

MEIRELLES, A. M. O.. Planejamento Estratégico no Banco Central do Brasil e a Viabilidade Estratégica em uma Unidade Descentralizada da Autarquia: Um Estudo de Caso. Dissertação (Mestrado) - Universidade de Minas Gerais, Belo Horizonte, 1995.

NOVAIS, H.. A Flexibilidade Estratégica. In: GONÇALVES, V. C. et al.. Gestão Estratégica. Coimbra: Conjuntura Actual, 2017. p.147-180.
PISCOPO, M. R.. Empreendedorismo corporativo e competitividade em empresas de base tecnológica. Revista de Administração e Inovação, v.7, n.1, p.131-150, 2010.

PORTER, M. E.. Estratégia Competitiva: técnicas para a Análise de Indústrias e da Concorrência. Rio de Janeiro: Campus, 1986

PORTER, M. E.. Vantagem Competitiva: Criando e Sustentando um Desempenho Superior. Rio de Janeiro: Campus, 1989.

PORTER, M. E.. Competição: Estratégias Competitivas Essenciais. Rio de Janeiro: Campus, 1999.

RIBAULT, J. M.; MARTINET, B.; LEBIDOIS, D.. A Gestão das Tecnologias. Lisboa: Dom Quixote, 1995.

ROGERS, E. M.; SHOEMAKER, F. F.. Communication of Innovations. New York: Free Press, 1971.

SANCHES, P. L. B.; MACHADO, A. G. C.. Estratégias de inovação e RBV: Evidências em uma empresa de base tecnológica. Revista de Administração e Inovação, v.10, n.4, p.183-207, 2013.

SCHUMPETER, J. A.. A Teoria do Desenvolvimento Econômico. São Paulo, 1985.

SCHUMPETER, J. A.. A Instabilidade do Capitalismo. In: CARNEIRO, R.. Os Clássicos da Economia. São Paulo. Ática, 1997. p.68-96.

SCHUMPETER, J. A.. Teoria do desenvolvimento econômico: Uma teoria sobre lucros, capital, crédito, juro e o ciclo econômico. São Paulo: Nova Cultural, 1997.

SILVA, T. PEREIRA, M. F.; CÁRIO, S. A. F.. Considerações sobre inovação e atividade empreendedora da trajetória sulcoreana. Revista de Administração e Inovação, v.10, n.4, p.283-307, 2013.

TIDD, J.; BESSANT, J.; PAVITT, K.. Gestão da Inovação: Integração das Mudanças Tecnológicas, de Mercado e Organizacionais. Lisboa: Monitor, 2003.

VAN DER VEN, A. H.. Central Problems in the Management of Innovation. Management Science, v.32, n.5, p.590-607.

WRIGHT, P.; KROLL, M. J.; PARNELL, J.. Administração Estratégica: Conceitos. São Paulo: Atlas, 2000.

ZANCUL, E. S.; MARX, R.; METZKER, A.. Organização do trabalho no processo de desenvolvimento de produtos: a aplicação da engenharia simultânea em duas montadoras de veículos. Gestão \& Produção, São Carlos, v.13, n.1, p.15-29, 2006.

A CBPC - Companhia Brasileira de Produção Científica (CNPJ: 11.221.422/0001-03) detém os direitos materiais desta publicação. Os direitos referem-se à publicação do trabalho em qualquer parte do mundo, incluindo os direitos às renovaç̃es, expansões e disseminações da contribuição, bem como outros direitos subsidiários. Todos os trabalhos publicados eletronicamente poderão posteriormente ser publicados em coletâneas impressas sob coordenação da Sustenere Publishing da Companhia Brasileira de Produção Científica e seus parceiros autorizados. Os (as) autores (as) preservam os direitos autorais, mas não têm permissão para a publicação da contribuição em outro meio, impresso ou digital, em português ou em tradução. 